\section{Interpersonal attraction as a function of the type of favorable and
unfavorable evaluation}

JAY HEWITT

University of Missouri-Kansas City, Kansas City, Mo. 64110

The Ss received personal evaluations from three confederates and then rated their liking for each individual. Favorable evaluations produced more attraction than unfavorable evaluations regardless of whether they were consistent or inconsistent with S's perception of himself. The specific content of the evaluation was more important when the evaluation was unfavorable than when it was favorable. Different types of favorable evaluation were not associated with differential degrees of liking. Unfavorable evaluations that were inconsistent with S's pereption of himself produced greater hostility than those that were consistent with S's perception of himself.

According to the reward theory of interpersonal attraction, people are attracted to those who reward or reinforce them. One type of reward a person can receive from others is esteem. People tend to be more attracted to those who evaluate them favorably than to those who evaluate them unfavorably (Aronson \& Worchel, 1966; Backman \& Secord, 1959; Byrne \& Griffitt, 1966). As Aristotle has pointed out: "We feel friendly toward those who praise such good qualities as we possess ... toward those who are not evilspeakers and who are aware of neither their nieghbor's bad points nor our own, but of our good ones only ([translated 1924 , p. 1381." Although reward theory has been shown to be a viable model of interpersonal attraction, reward theory does not specify the type of favorable evaluation that will lead to the greatest attraction or the type of unfavorable evaluation that will lead to the greatest hostility.

According to the cognitive consistency theory of interpersonal attraction, the attraction of one person $(\mathrm{P})$ to another person $(\mathrm{O})$ is a function of the similarity between O's perception of $P$ and $P$ 's perception of himself (Deutsch \& Solomon, 1959). People are most attracted to those who see them as they see themselves. Some support for this proposition was obtained in a study by Hewitt (1969). Ss received evaluations that were either favorable or unfavorable and either accurate or relatively inaccurate. Accurate evaluations consisted of traits the $S$ had previously used to describe himself, while inaccurate evaluations consisted of traits another $\mathrm{S}$ had employed to describe himself. Accurate evaluations tended to generate higher attraction ratings than inaccurate evaluations.

The present study was designed to examine the generality of the relationship between accuracy of evaluation and liking. If a person were told that he possessed those characteristics he was striving to possess (but currently did not possess) or did not possess the undesirable characteristics he felt he did possess, this might serve to enhance his perception of himself and, as a consequence, lead to a relatively high evaluator. Even though such an evaluation would be inaccurate, it might lead to more attraction than an evaluation that merely reaffirmed the $S$ 's perception of his desirable characteristics. Conversely, there may be some situations in which accurate unfavorable evaluations would generate more hostility than inaccurate unfavorable evaluations. If a person were told that he did not possess those characteristics he was striving to possess, this might be a source of need frustration and, as a consequence, might generate a high degree of animosity toward the evaluator.

\section{DESIGN}

Each $S$ received three evaluations of himself, one from each of three different confederates, and then rated his liking for each evaluator. A 2 by 3 design was employed, with each evaluation being either favorable or unfavorable and based on (1) the S's desirable characteristics, (2) the S's ideal characteristics, or (3) the S's undesirable characteristics. Each $\mathrm{S}$ was told that he either possessed or did not possess the traits he had employed to describe his desirable characteristics, that he either possessed or did not possess the traits he had employed to describe his ideal characteristics (the traits he would most like to possess but currently did not possess), and that he either possessed or did not possess the traits he had employed to describe his undesirable characteristics. degree of attraction toward the
SUBJECTS

The Ss consisted of 30 males recruited from an introductory psychology course. Half of the Ss were assigned to the "favorable evaluation" condition, the remaining to the "unfavorable evaluation" condition.

\section{PROCEDURE}

Upon arriving for the experiment, the $\mathrm{S}$ was seated in a small soundproof cubicle and handed three lists of adjectives. On the first list, the $S$ was told to put a checkmark beside the five adjectives that best described his desirable characteristics, on the second list, a checkmark beside the five adjectives that best described the characteristics he would most like to possess (but currently did not possess), and on the third list, a checkmark beside the five adjectives that best described his undesirable characteristics. The $S$ was then informed that there were three other people participating in the experiment (Ss $A, B$, and $C$ ), that each $S$ was located in a different room, and that all rooms were connected via intercom. (In reality, $\mathrm{A}, \mathrm{B}$, and $\mathrm{C}$ were confederates.)

After the initial instructions had been given, the $\mathbf{S}$ was handed a sheet which summarized the procedure. The other people participating in the experiment would each be given a list on which there were five checked adjectives (the S's desirable, ideal, or undesirable characteristics). The $S$ would then be required to answer four questions about himself. $\mathrm{A}, \mathrm{B}$, and $\mathrm{C}$ would be able to hear these answers over their intercom, after which they would be asked to give their impression of the $S$.

The actual procedure was then carried out. Each confederate was given a list on which there were five checked adjectives. The $\mathrm{S}$ was then asked to describe his interests, his goals in life, the kind of people he liked and disliked, and his personal problems. After this information had been delivered (via intercom) to $\mathrm{A}, \mathrm{B}$, and $\mathrm{C}$, Person $\mathrm{A}$ was asked to go through each of the checked adjectives on his list. After naming each trait, Person A was asked to say whether or not that trait characterized or did not characterize the $S$. When $A$ was finished, similar instructions were given to $\mathrm{B}$ and then to $\mathrm{C}$. The $\mathrm{S}$ was able to hear these comments over his intercom. When all three evaluations had been delivered, the $\mathrm{S}$ was asked to rate his liking for $A, B$, and $C$ on a scale ranging from +10 (strong liking) to -10 (strong dislike), after which he was debriefed and then dismissed.

\section{EVALUATIONS}

In the favorable evaluation condition, Ss were told that they possessed the two sets of desirable 
Evaluation

\begin{tabular}{llll} 
List & \multicolumn{1}{c}{ Referent } & \multicolumn{1}{c}{$\begin{array}{c}\text { "Does } \\
\text { Possess Traits" }\end{array}$} & $\begin{array}{c}\text { "Does Not } \\
\text { Possess Traits" }\end{array}$ \\
\hline I & $\begin{array}{l}\text { Desirable Traits } \\
\text { S Ascribes to Self }\end{array}$ & $\begin{array}{l}\text { Favorable } \\
\text { Accurate }\end{array}$ & $\begin{array}{l}\text { Unfavorable } \\
\text { Inaccurate }\end{array}$ \\
II & $\begin{array}{l}\text { Desirable Traits } \\
\text { Ideal }\end{array}$ & $\begin{array}{l}\text { Favorable } \\
\text { Inaccurate }\end{array}$ & $\begin{array}{l}\text { Unfavorable } \\
\text { Accurate }\end{array}$ \\
III & Undesirable Traits & Unfavorable & Favorable \\
& S Ascribes to Self & Accurate & Inaccurate \\
\hline
\end{tabular}

for the Evaluator Evaluation

\begin{tabular}{|c|c|c|c|}
\hline List & Referent & Favorable & Unfavorable \\
\hline I & $\begin{array}{l}\text { Desirable Traits } \\
\text { S Ascribes to Self }\end{array}$ & $3.87 *$ & $-2.13^{* *}$ \\
\hline II & $\begin{array}{l}\text { Desirable Traits } \\
\text { Ideal }\end{array}$ & $3.93^{*}$ & $2.00 * *$ \\
\hline III & $\begin{array}{l}\text { Undesirable Traits } \\
\mathrm{S} \text { Ascribes to Self }\end{array}$ & $3.87^{* *}$ & $2.27^{*}$ \\
\hline
\end{tabular}

characteristics and did not possess the set of undesirable characteristics. One confederate (A, B, or C) felt that the $S$ possessed four of the traits on List 1 (traits used by $S$ to describe his desirable characteristics). One confederate felt that $S$ possessed four of the traits on List 2 (traits the $S$ would most like to possess but currently did not possess), and one confederate felt that $\mathrm{S}$ did not possess four of the traits on List 3 (traits used by the $\mathrm{S}$ to describe his undesirable characteristics). Confederate $\mathrm{A}$ was always unsure as to whether or not the $S$ possessed the first checked adjective on his list, B was unsure about the third checked adjective on his list, and $C$ was unsure about the fourth checked adjective on his list. The evaluations in the unfavorable evaluation condition were the mirror image of those in the favorable evaluation condition-Ss were told that they did not possess the two sets of desirable characteristics and did possess the set of undesirable characteristics. A more complete description of these evaluations is given in Table 1 .

\section{RESULTS}

Favorable evaluations produced more attraction than unfavorable evaluations. The specific content of the evaluation was relatively unimportant when the evaluation was favorable but was a relevant variable when the evaluation was unfavorable. The inaccurate unfavorable evaluation generated more hostility than the two unfavorable evaluations that were consistent with the S's perception of himself. The means are presented in Table 2.

A Type I analysis of variance was carried out on the data (Lindquist, 1953 , p. 267). Favorable evaluations generated more attraction than unfavorable evaluations $(F=8.61$; df $=2 / 56 ; p<.01)$, and there was a significant interaction between the type of evaluation (favorable vs unfavorable) and the list of checked adjectives on which the evaluation was based $(F=13.82 ; \quad d f=1 / 28$; $p<.001)$. The specific content of the evaluation appeared to be more important when the evaluation was unfavorable than when it was favorable. Different types of favorable evaluations were not associated with differential degrees of liking. Content was an important variable when the evaluation was unfavorable, with the inaccurate unfavorable evaluation generating more hostility than either of the two accurate unfavorable evaluations $(\mathrm{t}=3.86$ and 3.22 $\mathrm{df}=14 ; \mathrm{p}<.01$, for both). Ss were less attracted to someone who said they did not possess the desirable characteristics they felt they did possess than (1) someone who said they did not possess their ideal characteristics and (2) someone who said they did possess their undesirable characteristics.

\section{DISCUSSION}

The results were generally consistent with reward theory. Favorable evaluations produced more attraction than unfavorable evaluations. Contrary to the cognitive consistency theory of interpersonal attraction, accuracy was not a relevant variable when the evaluation was favorable. Favorable evaluations appeared to generate a high degree of attraction with the specific content of the evaluation being relatively unimportant. People apparently like to be flattered and tend to accept such a communication regardless of whether the flattery is genuine or totally inaccurate.

Consistency theory also failed to receive support when accuracy and favorability were opposed to one another. Accurate unfavorable evaluations did not generate more attraction than inaccurate favorable evaluations. In fact, just the reverse tended to be true. Pointing out a person's undesirable characteristics would appear to lead to less attraction than telling him that he had desirable characteristics which in fact he did not possess. When reward and cognitive consistency theory make differential predictions, reward theory appears to be a more viable model of interpersonal attraction.

Cognitive consistency theory was supported when the evaluations were unfavorable. As in the Hewitt (1969) study, inaccurate unfavorable evaluations generated more hostility than accurate unfavorable evaluations. When such an evaluation is consistent with the S's perception of himself, the communication is apparently accepted, and the $S$ remains relatively neutral toward the communicator. When the evaluation is inconsistent with the S's perception of himself, however, it would appear that both the communication and the communicator tend to be rejected.

\section{REFERENCES}

ARISTOTLE. The works of Aristotle translated into English. Vol. II. Oxford: Clarenden Press, 1924.

ARONSON, E., \& WORCHEL, P. Similarity versus liking as determinants of interpersonal attractiveness. Psy chonomic Science, 1966, 5, 157-158.

BACKMAN, C. W., \& SECORD, P. F. The effect of perceived liking on interpersonal attraction. Human Relations, 1959, 12 379-384.

BYRNE, D.. \& GRIFFITT, W. Similarity versus liking: A clarification. Psychonomic Science, 1966, 6, 295-296.

DEUTSCH, M., \& SOLOMON, L. Reactions to evaluations by others as influenced by selfevaluations. Sociometry, 1959, 22 , 93-112.

HEWITT, J. Interpersonal attraction as a function of the accuracy of personal evaluations. Psychonomic Science, 1969 17, 95-96.

LINDQUIST, E. F. Design and analysis of experiments in psychology and education. Cambridge, Mass: Houghton-Mifflin, 1953. 